\title{
The health benefits of selective taxation as an economic instrument in relation to IHD and nutrition-related cancers
}

\author{
Astrid L Holm ${ }^{1, *}$, Mai-Britt Laursen ${ }^{1}$, Maria Koch ${ }^{1}$, Jørgen D Jensen ${ }^{2}$ and \\ Finn Diderichsen ${ }^{1}$ \\ 'Department of Public Health, Section of Social Medicine, University of Copenhagen, CSS, Øster Farimagsgade \\ 5, DK-1014 Copenhagen, Denmark: ${ }^{2}$ Institute of Food and Resource Economics, University of Copenhagen, \\ Copenhagen, Denmark
}

Submitted 9 May 2012: Final revision received 13 December 2012: Accepted 4 January 2013: First published online 11 February 2013

\begin{abstract}
Objective: The present study aimed to estimate the health benefits of selective taxation of healthy and unhealthy food commodities in relation to CVD and nutrition-related cancers.

Design: The potential health effects of a selective taxation scenario were estimated as changes in the burden of disease, measured by disability-adjusted life years, from health outcomes affected by the changes in food intake. The change in burden of a disease was calculated as the change in incidence of the disease due to a modified exposure level, using the potential impact fraction. Estimates of relative risk for the associations between various foods and relevant diseases were found through a literature search and used in the calculation of potential impact fractions.

Setting: The study was based in Denmark, estimating the health effects of a Danish selective taxation scenario.

Subjects: The potential health effects of selective taxation were modelled for the adult Danish population.

Results: Halving the rate of value-added tax on fruit and vegetables and increasing the tax on fats would result in moderate reductions in the burden of disease from IHD, ischaemic stroke, and colorectal, lung and breast cancer $(0 \cdot 4-2 \cdot 4 \%$ change $)$. The largest effect could be obtained through increased intake of fruit and vegetables (0.9-2.4\%).

Conclusions: Applying selective taxation to healthy and unhealthy foods can moderately reduce the burden of disease in the Danish population.
\end{abstract}

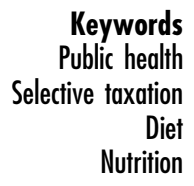

The diet of the Danish population generally does not live up to the Danish dietary recommendations; only a small proportion of the population eats the recommended $600 \mathrm{~g}$ of fruit and vegetables daily, and few Danes receive the daily amount of dietary fibre prescribed by the recommendations ( $25 \mathrm{~g}$ for women and $35 \mathrm{~g}$ for men). Further, the average energy intake from fat and saturated fat in the adult Danish population is higher than recommended (respectively maximum $30 \%$ and $10 \%$ of total energy intake $)^{(1,2)}$.

In the area of nutrition policy, applying differential or selective taxation to healthy and unhealthy food commodities has often been suggested as an economic instrument to encourage the population to eat a healthier diet and thereby improve public health ${ }^{(3-5)}$.

Only limited research exists regarding how price influences the demand for food commodities and how a population's diet will be affected by selective taxation ${ }^{(6-8)}$. Studies of the effects of selective taxation have primarily analysed the demand for food commodities, without considering the possible effects on public health. However, a large body of research exists on the relationship between nutrition and disease, suggesting that selected food categories particularly affect the risk of heart disease and certain cancers ${ }^{(9-14)}$. Analyses of the potential health effects of changes in demand for food commodities due to selective taxation are therefore needed.

The objective of the present study was to estimate the health benefits of applying a scenario of selective taxation to certain healthy and unhealthy food commodities in Denmark. The analysed selective taxation scenario involved halving the rate of value-added tax (VAT) on fruit and vegetables and increasing taxation on fats and sugar. The health benefits were estimated in terms of disability-adjusted life years (DALY) in relation to IHD, ischaemic stroke, colorectal cancer, lung cancer and breast cancer. 


\section{Methods}

The methodology for analysing the potential health gains from selective taxation consists of two separate analytical steps (Fig. 1). First, the change in demand for certain foods due to selective taxation is estimated; second, based on this, the potential health benefits of changed demand is calculated. Our study focused on the latter of these two analytical steps.

Results from the first analytical step were derived from a Danish study that estimated the changed demand for fruit and vegetables, fibre, fat, saturated fat and sugar due to a selective taxation scheme ${ }^{(6)}$. Using econometric methods, the price elasticities were estimated from data generated by Statistics Denmark for 1971-1996 ${ }^{(15)}$. The study analysed a hypothetical scenario in which VAT on fruit and vegetables was halved (from $25 \%$ to $12.5 \%$ ) and taxation was increased on fats (to approximately DKK 8.00 (=€ 1.08*) per kilogram of fat) and sugar (to approximately DKK 5.60 (=€ 0.75*) per kilogram of sugar). This taxation scenario resulted in an increased demand for fruit and vegetables $(+7 \cdot 6 \%)$ and fibre $(+4 \cdot 3 \%)$ and a reduced demand for fat $(-5 \cdot 1 \%)$, saturated fat $(-2 \cdot 9 \%)$ and sugar $(-3 \cdot 1 \%)$.

Based on these results we estimated the health benefits of changes in demand, assuming that the changed demand for the included food commodities corresponded to a change in intake. The potential health effects of selective taxation were estimated as changes in the burden of disease, measured by DALY, from health outcomes affected by the changes in food intake. Change in burden of disease was calculated using the potential impact fraction (PIF), an epidemiological method to determine the effect of an exposure on population health, expressed as the change in incidence of disease if the exposure level is modified ${ }^{(16,17)}$. Estimation of PIF required the following input data: (i) the proportion of the population exposed before and after changes in demand and (ii) estimates of relative risk (RR) for the relationships between exposures and health outcomes.

Further, to estimate the maximum health effect of changes in diet, the population-attributable fraction (PAF) was estimated. PAF refers to the hypothetical situation in which the exposure is eliminated ${ }^{(18)}$, indicating that the food intake of the entire population complies with the national nutritional recommendations.

Exposure was defined according to the Danish National Nutritional Recommendations $\uparrow$ The exposed proportion of the population was defined as the proportion of the Danish population whose food intake did not conform to the recommendations, whereas non-exposure was defined

\footnotetext{
* Exchange rate: $€ 100=$ DKK 743.67 (9 May 2012).

$\uparrow$ The Danish nutritional recommendations for women and men respectively are: fruit and vegetables, $600 \mathrm{~g} / \mathrm{d}$ (both sexes); sugar, $55 \mathrm{~g}$
} and $70 \mathrm{~g}$ daily maximum; and fats, $75 \mathrm{~g}$ and $95 \mathrm{~g}$ daily maximum ${ }^{(19)}$. as the proportion of the population whose food intake did conform to the recommendations. The exposed segment was divided into two subgroups, the moderately exposed and the highly exposed, since different levels of exposure are associated with different relative risks. The highly exposed subgroup was defined as those individuals whose food intake exceeded (fell below) the mean intake by plus (minus) the standard deviation; i.e. those whose intake differed substantially from the national nutritional recommendations. Moderately exposed individuals were defined as those with an intake between the high exposure threshold and the level corresponding to the nutritional recommendations. The median value of each group was used as point estimate of exposure in the highly exposed and moderately exposed, respectively. Figure 2 illustrates the exposure levels.

The proportions of exposed and non-exposed individuals at baseline, e.g. prior to selective taxation, were calculated from a Danish survey on food consumption ${ }^{(1,2)}$. The survey data were collected through a $7 \mathrm{~d}$ food record in a pre-coded (semi-closed) questionnaire. Data regarding food nutrient content were taken from The National Food Institute's Food Composition Databank ${ }^{(1)}$.

Change in exposed individuals was calculated from the change in food intake due to selective taxation. In this calculation it was assumed that the food intake approximated a normal distribution, allowing for the proportion of exposed individuals to be estimated based on a standardized normal distribution. Additionally, it was assumed that the absolute change in food intake due to taxation was the same in the entire population. Given these two assumptions, selective taxation of foods would result in a parallel displacement of the food intake, where only the mean value changed while the variance and shape were maintained. Information regarding baseline mean intake of different foods and the standard deviation for this intake in Denmark was taken from Fagt et $a l^{(2)}$, and the results from Jensen and Smed ${ }^{(6)}$ were used as estimates of change in mean intake of the different foods.

Estimates of RR for associations between exposures (the included food and nutrient categories) and relevant health outcomes (CVD and nutrition-related cancers) were found through a literature search using MEDLINE. We focused the literature search on meta-analyses, but included results from individual studies for associations where no meta-analyses could be identified. Studies of indirect relationships, such as those involving intermediate variables (e.g. overweight), were excluded. If more studies of the same association were found, the RR estimate to be used in the analyses was chosen based on the validity of the studies.

If the RR estimates found in the literature did not correspond to the exposure levels being contrasted in our study (highly exposed $v$. not exposed and moderately exposed $v$. not exposed, as described above), the RR estimates were recalculated to reflect the relevant exposure levels. This was done based on the exposure 


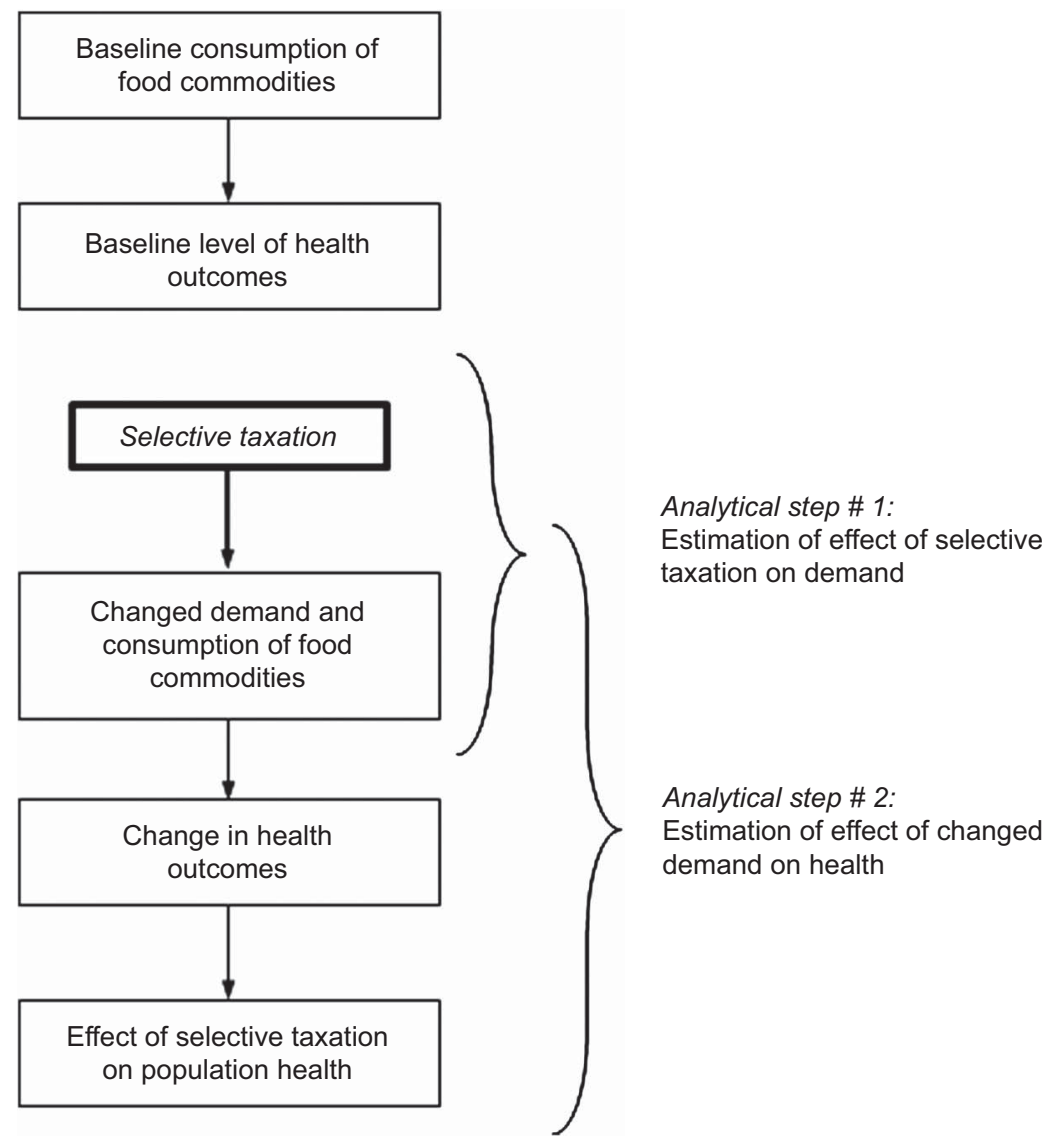

Fig. 1 Overview of the methodology for analysing potential public health gains of selective taxation on food commodities

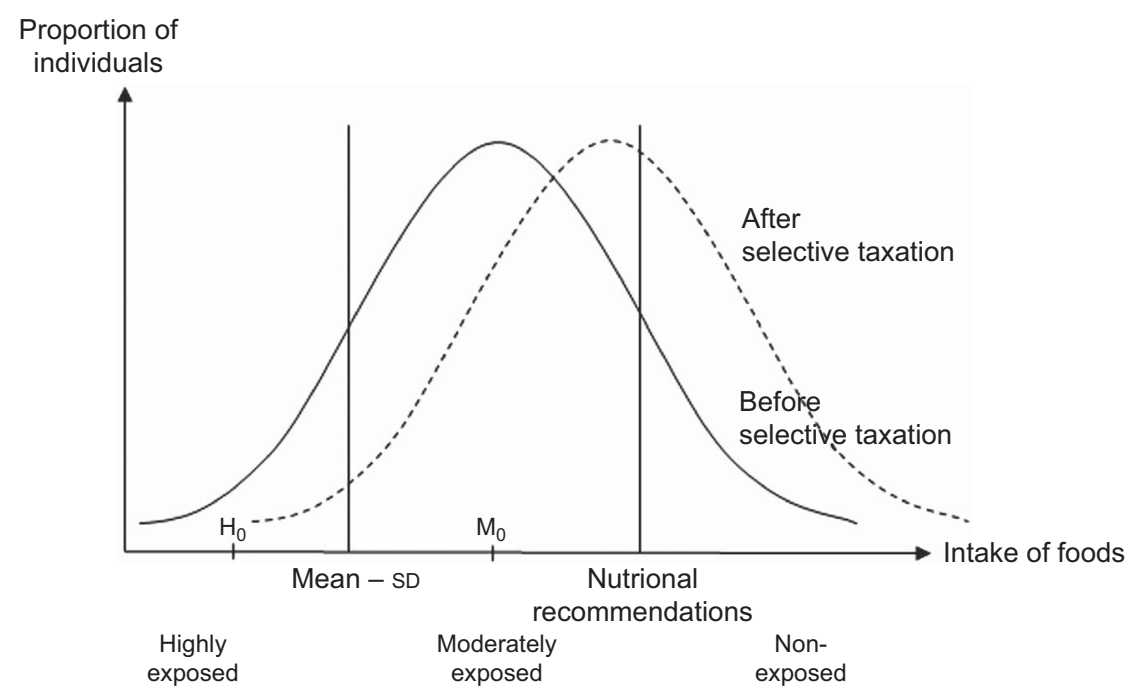

Fig. 2 Illustration of the proportions of highly exposed, moderately exposed and non-exposed individuals before and after selective taxation. Baseline distribution (before taxation) is shown by the line - whereas the distribution of exposure after taxation is shown by the line - - -, illustrating how taxation would shift parts of the population towards a diet closer to the national nutritional recommendations, thereby decreasing the proportion of exposed individuals. $\mathrm{H}_{0}$ illustrates the median value for highly exposed and $\mathrm{M}_{0}$ the median value for moderately exposed. The plot illustrates exposure and changed exposure for foods where a high intake is recommended (e.g. fruit and vegetables)

levels described in the original study and assuming a linear relationship between intake of the relevant food commodities and occurrence of the particular diseases.
Exposure-outcome associations for which the literature showed evidence of significant associations were included in the analyses. PIF, PAF and change in DALY were 
calculated for all included associations. For all diseases, the WHO's most recent estimates of burden of disease in Denmark (from 2004) were used to indicate the baseline burden of disease ${ }^{(20)}$. The calculations were performed in Microsoft ${ }^{\circledR}$ Excel, using the add-in Ersatz (version 1.3) for uncertainty analyses and calculation of confidence intervals.

\section{Results}

The literature review showed evidence of associations between intake of fruit and vegetables and IHD, ischaemic stroke and lung cancer ${ }^{(10)}$. For fibre it was relevant to include the association with IHD, colorectal cancer and breast cancer $^{(21-23)}$. For both fat and saturated fat evidence was found only for an association with breast cancer ${ }^{(24)}$, and the estimates of relative risk for this association were categorical, comparing only high and low intake of fats. We did not find sufficient evidence for effects of sugar (in non-diabetics) to include this nutrient in the analyses. Table 1 shows the RR estimates used in the analyses.

Table 2 shows the potential impact of the selective taxation scenario (estimated in DALY per 100000 people). The largest reductions in burden of disease could be obtained from decreased IHD and ischaemic stroke if the intake of fruit and vegetables was increased. Comparing the four included nutritional exposures, the biggest reduction in burden of disease could be obtained through changed demand for fruit and vegetables (32.9 DALY per 100000 people), followed by fibre (11.0 DALY per 100000 people), fat (2.4 DALY per 100000 people) and saturated fat (1.8 DALY per 100000 people). The health impact of the selective taxation scenario thus differed for the included dietary risk factors.

To illustrate the maximum health effect potentially obtainable through changed intake of the included food commodities, Table 3 shows the effect on burden of disease from the selected health outcomes if the food intake of the entire Danish population complied with the national nutritional recommendations. In this scenario, the largest reduction in burden of disease could be obtained from IHD (242.8 DALY per 100000 people) through increased intake of fruit and vegetables. For the dietary risk factors the biggest reduction in burden of disease could be obtained if the entire population increased its intake of fruit and vegetables $(367 \cdot 2$ DALY per 100000 people), followed by fibre (136.2 DALY per 100000 people), and reduced its intake of saturated fat ( 8.3 DALY per 100000 people) and fat (5.7 DALY per 100000 people).

\section{Discussion}

\section{Discussion of results}

Our analyses show that selective taxation of fruit and vegetables, fibre and fats could result in a reduction of the burden of disease from the five nutrition-related diseases included in the study. The biggest reductions in the burden of disease could be obtained from increased intake of fruit and vegetables and fibre. Of the included nutritional exposures, low intake of fruit and vegetables also involved the greatest relative risks for the included associations with health outcomes.

Table 1 Estimates of relative risk used in the analyses for highly exposed and moderately exposed individuals

\begin{tabular}{|c|c|c|c|c|c|c|c|c|}
\hline \multirow[b]{3}{*}{ Health outcome } & \multicolumn{8}{|c|}{ Nutritional exposure } \\
\hline & \multicolumn{2}{|c|}{ Fruit and vegetables } & \multicolumn{2}{|c|}{ Fibre } & \multicolumn{2}{|c|}{ Fat } & \multicolumn{2}{|c|}{ Saturated fat } \\
\hline & $\mathrm{RR}$ & $95 \% \mathrm{Cl}$ & $\mathrm{RR}$ & $95 \% \mathrm{Cl}$ & $\mathrm{RR}$ & $95 \% \mathrm{Cl}$ & $\mathrm{RR}$ & $95 \% \mathrm{Cl}$ \\
\hline IHD & & & & & - & - & - & - \\
\hline High risk & $1 \cdot 93^{*}$ & $1 \cdot 08,3 \cdot 51$ & $1 \cdot 33 t$ & $1 \cdot 10,1 \cdot 63$ & & & & \\
\hline Moderate risk & $1 \cdot 30^{\star}$ & $1 \cdot 03,1 \cdot 65$ & $1 \cdot 10 t$ & $1 \cdot 03,1 \cdot 18$ & & & & \\
\hline Ischaemic stroke & & & - & - & - & - & - & - \\
\hline High risk & $1 \cdot 47^{*}$ & $1 \cdot 06,2 \cdot 05$ & & & & & & \\
\hline Moderate risk & $1 \cdot 17^{*}$ & $1 \cdot 02,1 \cdot 33$ & & & & & & \\
\hline Colorectal cancer & - & - & & & - & - & - & - \\
\hline High risk & & & $1 \cdot 22 \ddagger$ & $1 \cdot 12,1 \cdot 33$ & & & & \\
\hline Moderate risk & & & $1 \cdot 07 \ddagger$ & $1 \cdot 04,1 \cdot 10$ & & & & \\
\hline Lung cancer & & & - & - & - & - & - & - \\
\hline High risk & $1 \cdot 29^{\star}$ & $1 \cdot 06,1 \cdot 57$ & & & & & & \\
\hline Moderate risk & $1 \cdot 11^{*}$ & $1 \cdot 02,1 \cdot 20$ & & & & & & \\
\hline Breast cancer & - & - & & & & & & \\
\hline High risk & & & $1 \cdot 15 \S$ & $1 \cdot 04,1 \cdot 27$ & $1 \cdot 13 \|$ & $1 \cdot 02,1 \cdot 25$ & $1 \cdot 19 \|$ & $1 \cdot 05,1 \cdot 34$ \\
\hline Moderate risk & & & $1 \cdot 05 \S$ & $1 \cdot 01,1 \cdot 09$ & - & - & - & - \\
\hline
\end{tabular}

$\mathrm{RR}$, relative risk.

- indicates that no or insufficient evidence was found for the given association.

${ }^{*}$ Calculated for the relevant exposure level based RR estimates from Lock et al. $(2004)^{(10)}$

tCalculated for the relevant exposure level based RR estimates from Pereira et al. (2004) ${ }^{(21)}$.

$\ddagger$ Calculated for the relevant exposure level based RR estimates from Aune et al. $(2011)^{(22)}$.

§Calculated for the relevant exposure level based RR estimates from Dong et al. $(2011)^{(23)}$.

IIRR estimates for high $v$. low intake from Boyd et al. $(2003)^{(24)}$, no increase in risk was assumed for moderate exposure. 
Table 2 The potential impact of the analysed selective taxation scenario. Effect illustrated as absolute (DALY per 100000 people) and relative (PIF) change in DALY compared with baseline for each association between nutritional exposures and health outcomes and summed for each nutritional exposure

\begin{tabular}{|c|c|c|c|c|c|c|c|c|c|}
\hline \multirow[b]{3}{*}{ Health outcome } & \multirow{3}{*}{$\begin{array}{l}\text { Baseline DALY for } \\
\text { health outcome }\end{array}$} & \multicolumn{8}{|c|}{ Nutritional exposure } \\
\hline & & \multicolumn{2}{|c|}{ Fruit and vegetables } & \multicolumn{2}{|c|}{ Fibre } & \multicolumn{2}{|c|}{ Fat } & \multicolumn{2}{|c|}{ Saturated fat } \\
\hline & & PIF (\%) & DALY & PIF (\%) & DALY & PIF (\%) & DALY & PIF (\%) & DALY \\
\hline IHD & 910 & $2 \cdot 4$ & $21 \cdot 9$ & 0.9 & $7 \cdot 9$ & - & - & - & - \\
\hline Ischaemic stroke & $462^{*}$ & $1 \cdot 4$ & $6 \cdot 4$ & - & - & - & - & - & - \\
\hline Colorectal cancer & 324 & - & - & $0 \cdot 6$ & $1 \cdot 9$ & - & - & - & - \\
\hline Lung cancer & 502 & $0 \cdot 9$ & $4 \cdot 6$ & - & - & - & - & - & - \\
\hline Breast cancer & 284 & - & - & $0 \cdot 4$ & $1 \cdot 2$ & $0 \cdot 8$ & $2 \cdot 4$ & $0 \cdot 6$ & $1 \cdot 8$ \\
\hline \multirow{2}{*}{\multicolumn{2}{|c|}{$\begin{array}{l}\text { Total change in DALY for exposure } \\
\text { Sum } \\
95 \% \mathrm{Cl}\end{array}$}} & \multirow{2}{*}{\multicolumn{2}{|c|}{$\begin{array}{c}32 \cdot 9 \\
10 \cdot 3,58 \cdot 2\end{array}$}} & \multirow{2}{*}{\multicolumn{2}{|c|}{$\begin{array}{c}11 \cdot 0 \\
5 \cdot 6,17 \cdot 1\end{array}$}} & \multirow{2}{*}{\multicolumn{2}{|c|}{$\begin{array}{c}2 \cdot 4 \\
0 \cdot 5,4 \cdot 4\end{array}$}} & & \\
\hline & & & & & & & & \multicolumn{2}{|c|}{$\begin{array}{c}1 \cdot 8 \\
0 \cdot 5,3 \cdot 1\end{array}$} \\
\hline
\end{tabular}

DALY, disability-adjusted life years; PIF, potential impact fraction.

- indicates that no or insufficient evidence was found for the given association.

"WHO's estimate of burden of disease from stroke covers both ischaemic and haemorrhagic stroke. However, only ischaemic stroke was associated with intake of fruit and vegetables ${ }^{(10)}$. Assuming equal burden of disease from the two outcomes, burden of disease from ischaemic stroke was calculated as the relative share of ischaemic stroke in Denmark $(80-85 \%)^{(32)}$.

Table 3 Potential health effect if the diet of the entire Danish population complied with the national nutritional recommendations. Effect illustrated as absolute (DALY per 100000 people) and relative (PAF) change in DALY compared with baseline for each association between nutritional exposures and health outcomes and summed for each nutritional exposure

\begin{tabular}{|c|c|c|c|c|c|c|c|c|c|}
\hline \multirow[b]{3}{*}{ Health outcome } & \multirow{3}{*}{$\begin{array}{l}\text { Baseline DALY for } \\
\text { health outcome }\end{array}$} & \multicolumn{8}{|c|}{ Nutritional exposure } \\
\hline & & \multicolumn{2}{|c|}{ Fruit and vegetables } & \multicolumn{2}{|c|}{ Fibre } & \multicolumn{2}{|c|}{ Fat } & \multicolumn{2}{|c|}{ Saturated fat } \\
\hline & & PAF (\%) & DALY & PAF (\%) & DALY & PAF (\%) & DALY & PAF (\%) & DALY \\
\hline IHD & 910 & $26 \cdot 7$ & $242 \cdot 8$ & $10 \cdot 7$ & $97 \cdot 1$ & - & - & - & - \\
\hline Ischaemic stroke & $462^{*}$ & $16 \cdot 3$ & $75 \cdot 3$ & - & - & - & - & - & - \\
\hline Colorectal cancer & 324 & - & - & $7 \cdot 5$ & $24 \cdot 3$ & - & - & - & - \\
\hline Lung cancer & 502 & $9 \cdot 8$ & $49 \cdot 0$ & - & - & - & - & - & - \\
\hline Breast cancer & 284 & - & - & $5 \cdot 2$ & $14 \cdot 7$ & $2 \cdot 0$ & $5 \cdot 7$ & $2 \cdot 9$ & $8 \cdot 3$ \\
\hline \multicolumn{10}{|c|}{ Total change in DALY for exposure } \\
\hline Sum & & \multirow{2}{*}{\multicolumn{2}{|c|}{$\begin{array}{c}367 \cdot 2 \\
124 \cdot 0,582 \cdot 7\end{array}$}} & \multirow{2}{*}{\multicolumn{2}{|c|}{$\begin{array}{c}136 \cdot 2 \\
70 \cdot 9,205 \cdot 2\end{array}$}} & \multirow{2}{*}{\multicolumn{2}{|c|}{$\begin{array}{c}5 \cdot 7 \\
1 \cdot 2,10 \cdot 7\end{array}$}} & \multirow{2}{*}{\multicolumn{2}{|c|}{$\begin{array}{c}8 \cdot 3 \\
2 \cdot 3,14 \cdot 4\end{array}$}} \\
\hline $95 \% \mathrm{Cl}$ & & & & & & & & & \\
\hline
\end{tabular}

DALY, disability-adjusted life years; PAF, population-attributable fraction.

- indicates that no or insufficient evidence was found for the given association.

*WHO's estimate of burden of disease from stroke covers both ischaemic and haemorrhagic stroke. However, only ischaemic stroke was associated with intake of fruit and vegetables ${ }^{(10)}$. Assuming equal burden of disease from the two outcomes, burden of disease from ischaemic stroke was calculated as the relative share of ischaemic stroke in Denmark $(80-85 \%)^{(32)}$.

If the entire Danish population were to comply with the nutritional recommendations, much larger reductions in the burden of disease could be obtained, as shown in the analyses of PAF. Again, the largest potential health gain was obtainable through increased intake of fruit and vegetables.

In our analyses we only summarize the potential reductions in burden of disease for nutritional exposures. Because certain of the included nutritional risk factors share causal pathways, and therefore cannot be assumed to be independent, we did not summarize the reduction from each of the included health outcomes or the overall reduction from all included outcomes.

We analysed the health effects of the changes in food intake estimated to be the result of a reasonable selective taxation scenario $^{(6)}$. We were unable to find any studies that have analysed the health effects of similar changes in food intake. However, Lock et al. have estimated the worldwide contribution of low fruit and vegetables intake to the burden of disease ${ }^{(10)}$. They found that increasing the intake of fruit and vegetables to the nutritionally recommended level could reduce the burden of disease from IHD by $31 \%$, from ischaemic stroke by $19 \%$ and the burden from colorectal cancer by $2 \%{ }^{(10)}$. Compared with their results, our calculation of the PAF for intake of fruit and vegetables showed a smaller decrease in the burden of disease from IHD and ischaemic stroke but a larger decrease in the burden from colorectal cancer. These differences might be due to the results by Lock et al. being based on a large group of countries with different burdens of disease from the included diseases at baseline ${ }^{(10)}$.

Similarly, Beggs et al. have estimated the contribution of different risk factors to the burden of disease in Australia $^{(25)}$. They found that a low intake of fruit and vegetables caused $2 \cdot 1 \%$ of the total burden of disease 
and $1.4 \%$ of the total burden of disease from IHD, $0 \cdot 3 \%$ of the burden from ischaemic stroke and $0 \cdot 2 \%$ of the burden from colorectal cancer ${ }^{(25)}$. If we relate our analyses of PAF to the total burden of disease in Denmark (13447 DALY per 100000 people $^{(20)}$ ), we find that a low intake of fruit and vegetables caused $2 \cdot 8 \%$ of the total burden of disease and $1.8 \%, 0.7 \%$ and $0.4 \%$ of the burden of disease from IHD, ischaemic stroke and colorectal cancer, respectively. We thus find slightly higher burdens attributable to low fruit and vegetable intake than found in the Australian study.

\section{Discussion of methods}

Our results are affected by methodological uncertainties concerning the estimates of relative risk used in the analyses, assumptions about the normal distribution of food intake and DALY as the measure of the health effect of selective taxation.

A general limitation in prospective impact assessments is data availability. Our analyses of the potential reductions in burden of disease due to selective taxation are limited to nutritional exposures and health outcomes for which quantifiable evidence of health effects exists. We focused our literature search on meta-analyses, and chose to include only those health outcomes for which evidence of an association with a relevant nutritional exposure had been shown in meta-analyses. This might have caused us to exclude certain relevant associations, leading to a conservative estimate of the potential health effects of the analysed scenario of selective taxation. We also chose not to include health outcomes that could be characterized as intermediate outcomes (e.g. overweight) in our analyses.

Modelling potential future health impacts of selective taxation required certain assumptions. In the estimation of exposure before and after selective taxation we assumed that the intake of the included food categories was normally distributed. Based on data from the USA, it has been found that intake of fruit and vegetables is left-skewed, indicating that a larger proportion of the studied population consumes less fruit and vegetables than a normal distribution would suggest ${ }^{(10)}$. Results from a recent dietary survey suggest that the distribution of the intake of fruit and vegetables is similarly skewed in Denmark ${ }^{(26)}$. Hence the assumption of a normally distributed intake will underestimate the effect on burden of disease, since a distribution that is skewed towards a lower-than-estimated intake leads to a larger highly exposed proportion of the population. It was not possible to find data on the distribution of other food commodities.

The percentage effects of taxation changes were estimated on the basis of consumption figures from 2000-2002. Since then there has been a slight increase in the consumption levels of fruit and vegetables; this may imply that the potential health effects would be higher if the tax changes were implemented today, since a larger fraction of the consumers would then pass the recommended threshold as a result of the tax change. The applied price elasticities were estimated on the basis of consumption data from the period 1971-1996 and this may add some uncertainty when interpreting the results in a present setting, because consumers' price responsiveness may have evolved along with consumption trends and developments in prices and incomes. Correlations between changes in prices and consumed quantities of some of the nutritionally most relevant food categories suggest a weak trend towards lower price responsiveness in the demand for some of the food categories (which might suggest that the demand effects of the food taxation scheme would be overestimated), but the trend is not found to be statistically significant.*

The assumption of a standardized normal distribution of food intake implies the potential for a parallel displacement of the distribution. However, if the change in intake due to taxation differs between the highly exposed, moderately exposed and non-exposed groups, the actual proportion of individuals in each group would differ from the proportions estimated from a standardized normal distribution. A study of dietary changes in Denmark from 1985 to 2001 found that the intake of fruit and vegetables changed by the same absolute amount across the whole population, indicating that the assumption of a standardized normal distribution is reasonable for the intake of fruit and vegetables ${ }^{(2)}$. The same study indicated that the assumption was less certain for the intake of fats: individuals who had a high intake of fat were less likely than moderate consumers to change this intake ${ }^{(2)}$. Thus our estimates of change in health due to changes in intake of fats might be overestimated, since the highly exposed individuals are the main contributors to the change in burden of disease.

The use of fiscal measures as instruments in health promotion policy is not very widespread. Whereas examples taxing unhealthy foods and beverages (such as chocolate, sweets and sugared soft drinks) exist, general subsidization or tax reduction on healthy foods is rare or non-existent, and the political will to introduce such schemes might be even harder to imagine in times with tight public sector budgets. Nevertheless, the food taxation reform analysed in the present paper is designed to be neutral in terms of tax revenue, which might make the scheme more politically feasible, although it may still imply various transaction costs, for example in terms of defining products to be taxed or to be exempt from taxation.

In our analyses, DALY was used as the measure of health. DALY expresses the combined effect of disability and mortality, which is advantageous when analysing the effect of policies, since the effect of mortality and

\footnotetext{
* Unpublished analyses based on data from Statistics Denmark.
} 
disability might vary for different outcomes ${ }^{(27,28)}$. DALY was chosen in order to achieve comparability and validity by basing the estimations on epidemiological evidence of disease-specific associations, impact calculations and WHO's burden of disease calculations ${ }^{(29)}$. However, the use of DALY entails certain assumptions, including that the duration and severity (disability weight) of the included diseases does not change following selective taxation. Further, DALY involves certain value judgements, e.g. discounting and age weighting, which are being debated ${ }^{(30,31)}$.

Previous research has shown that monetary incentives such as selective taxation of food commodities can be effective in modifying dietary behaviour ${ }^{(6-8)}$. Our results support these findings and point to the conclusion that selective taxation can be included in health policies to contribute to reducing the burden of disease from diet-related diseases.

However, there are gaps in the evidence of the effects of monetary incentives and dietary behaviour, and more research is needed to address these. This includes evidence on the most efficient ways to design and implement taxation schemes, the possible differential effects on population subgroups with different risk profiles and measures of cost-effectiveness.

\section{Conclusion}

We analysed the potential health effects of a scenario where selective taxation was applied to healthy (fruit and vegetables and fibre) and unhealthy food commodities (fat and saturated fat). Our results show that selective taxation could result in a moderate reduction in the burden of disease from nutritionally related diseases. Our study illustrates that selective taxation of food commodities is an economic instrument that can be applied as a component of health policy to produce health gains and reduce the burden of disease.

\section{Acknowledgements}

Source of funding: This research received no specific grant from any funding agency in the public, commercial or not-for-profit sectors. Conflicts of interest: None of the authors have any conflicts of interest, or have relationships or activities that could appear to have influenced the submitted work. Ethics: Ethical approval was not required for this study. Authors' contributions: A.L.H. contributed to data analysis and writing of the article. M.-B.L. and M.K. contributed to the design of the study, data analysis and writing of the article. F.D. contributed to the design of the study, interpretation of data and drafting of the article. J.D.J. contributed to data interpretation and important revisions of article drafts. All authors approved the final version of the article.

\section{References}

1. Lyhne N, Christensen T, Groth M et al. (2005) Danskernes kostvaner 2000-2002-Hovedresultater (The Diet of Danes 2000-2002 - Main Results). Copenhagen: The Danish Institute for Food and Veterinary Research.

2. Fagt S, Mathiessen J, Biltoft-Jensen A et al. (2004) Udviklingen $i$ danskernes kost 1985-2001-med fokus på sukker og alkohol, samt motivation og barrierer for sund livsstil (Development in the Diet of Danes 1985-2001 Focused On Sugar and Alcohol, and Motivation and Barriers for a Healthy Lifestyle). Copenhagen: The Danish Institute for Food and Veterinary Research.

3. Elinder L (2004) The EU Common Agricultural Policy from a public health perspective. Eurohealth 10, 13-16.

4. Robertson A, Tirado C, Lobstein T et al. (editors) (2004) Food and Health in Europe: A New Basis for Action. WHO Regional Publications, European Series, no. 96. Copenhagen: WHO Regional Office for Europe.

5. Veerman JL, Barendregt JJ \& Mackenbach JP (2006) The European Common Agricultural Policy on fruits and vegetables: exploring potential health gain from reform. Eur J Public Health 16, 31-35.

6. Jensen J \& Smed S (2007) Cost-effective design of economic instruments in nutrition policy. Int J Behav Nutr Phys Act 4, 10.

7. Mytton O, Gray A, Rayner M et al. (2007) Could targeted food taxes improve health? J Epidemiol Community Health 61, 689-694.

8. Wall J, Mhurchu CN, Blakely T et al. (2006) Effectiveness of monetary incentives in modifying dietary behavior: a review of randomized, controlled trials. Nutr Rev 64, 518-531.

9. Danaei G, Vander HS, Lopez AD et al. (2005) Causes of cancer in the world: comparative risk assessment of nine behavioural and environmental risk factors. Lancet 366, 1784-1793.

10. Lock K, Pomerleau J, Causer L et al. (2004) Low fruit and vegetable consumption. In Comparative Quantification of Health Risks. Global and Regional Burden of Disease Attributable to Selected Major Risk Factors, vol. 1, pp. 597-728 [M Ezzati, A Lopez, A Rodgers et al., editors]. Geneva: WHO.

11. International Agency for Research on Cancer (2003) IARC Handbooks of Cancer Prevention. Lyon: IARC Press.

12. Pomerleau J, McKee M, Lobstein T et al. (2003) The burden of disease attributable to nutrition in Europe. Public Health Nutr 6, 453-461.

13. van't Veer P, Jansen MC, Klerk M et al. (2000) Fruits and vegetables in the prevention of cancer and cardiovascular disease. Public Health Nutr 3, 103-107.

14. World Cancer Research Fund/American Institute for Cancer Research (1997) Food, Nutrition and the Prevention of Cancer. Washington, DC: AICR.

15. Jensen J \& Toftkær L (2002) En økonometrisk model for fødevareefterspørgslen i Danmark (An Econometric Model of Food Demand in Denmark). Copenhagen: Institute of Food and Resource Economics, Faculty of Life Sciences, University of Copenhagen.

16. Morgenstern H \& Bursic ES (1982) A method for using epidemiologic data to estimate the potential impact of an intervention on the health status of a target population. J Community Health 7, 292-309.

17. Murray CJL, Ezzati M, Lopez AD et al. (2004) Comparative quantification of health risks: conceptual framework and methodological issues. In Comparative Quantification of Health Risks. Global and Regional Burden of Diseases Attributable to Selected Major Risk Factors, vol. 1, pp. 1-38 [M Ezzati, AD Lopez, A Rodgers et al., editors] Geneva: WHO.

18. Rothman KJ, Greenland S \& Lash TL (2008) Modern Epidemiology. Philadelphia, PA: Lippencott Williams \& Wilkins. 
19. Astrup A, Andersen N, Stender S et al. (2005) The Danish Dietary Recommendations 2005. Copenhagen: The Danish Institute for Food and Veterinary Research and the Danish Nutritional Council.

20. World Health Organization (2009) Disease and injury country estimates for 2004. http://www.who.int/healthinfo/ global_burden_disease/estimates_country/en/index.html (accessed October 2012).

21. Pereira MA, O'Reilly E, Augustsson K et al. (2004) Dietary fiber and risk of coronary heart disease: a pooled analysis of cohort studies. Arch Intern Med 164, 370-376.

22. Aune D, Chan DS, Lau R et al. (2011) Dietary fibre, whole grains, and risk of colorectal cancer: systematic review and dose-response meta-analysis of prospective studies. BMJ 343, d6617.

23. Dong JY, He K, Wang P et al. (2011) Dietary fiber intake and risk of breast cancer: a meta-analysis of prospective cohort studies. Am J Clin Nutr 94, 900-905.

24. Boyd NF, Stone J, Vogt KN et al. (2003) Dietary fat and breast cancer risk revisited: a meta-analysis of the published literature. Br J Cancer 89, 1672-1685.

25. Beggs S, Vos T, Barker B et al. (2007) The Burden of Disease and Injury in Australia 2003. Catalogue no. PHE 82. Canberra: AIHW, Australian Government.
26. Pedersen AN, Fagt S, Groth M et al. (2010) Danskernes Kostvaner 2003-2008 - Hovedresultater (The Diet of Danes 2003-2008 - Main Results). Lyngby: DTU Fødevareinstituttet.

27. Murray CJL \& Lopez AD (1996) The Global Burden of Disease - A Comprehensive Assessment of Mortality and Disability from Diseases, Injuries, and Risk Factors in 1990 and Projected to 2020. Cambridge, MA: Harvard University Press.

28. Field MJ \& Gold MR (1998) Summarizing Population Health, Directions for the Development and Application of Population Metrics. Washington, DC: National Academy Press.

29. Gold MR, Stevenson D \& Fryback DG (2002) HALYs and QALYs and DALYs, oh my: similarities and differences in summary measures of population health. Annu Rev Public Health 23, 115-134.

30. Anand S \& Hanson K (1997) Disability-adjusted life years: a critical review. J Health Econ 16, 685-702.

31. Murray CJ \& Acharya AK (1997) Understanding DALYs. $J$ Health Econ 16, 703-730.

32. Schroeder TV (2003) Basisbog i Medicin og Kirurgi (Textbook on Medicine and Surgery). Copenhagen: Munksgaard Denmark. 